A. Klimczuk, Activities of Daily Living, [in:] C. Shehan (ed.), The Wiley-Blackwell Encyclopedia of Family Studies, Wiley-Blackwell, Hoboken, New Jersey 2016, pp. 22-25.

http://doi.org/10.1002/9781119085621.wbefs 143

\title{
Activities of Daily Living
}

\section{ANDRZEJ KLIMCZUK}

Warsaw School of Economics, Poland

Activities of daily living (ADLs) are defined in healthcare as actions that are performed routinely by individuals in their everyday lives and that are necessary for living independent from family or outside help. They include activities performed both in the place of residence and in outdoor environments.

Measurement of ability or inability to perform ADLs is important in describing the functional status of a person and then in implementing an intervention. Evaluations of ADLs are mainly used in nursing and in rehabilitation of people with disabilities and the elderly. Measuring ADLs is also important in developing health research programs. Included in ADLs are mainly actions that maintain personal hygiene, consumption, and mobility. This health measure is one of the oldest and most widely used, and has been modified and expanded to evaluate changes in response to illness and to be adaptable to different clinical settings. Measurement of ADLs is crucial for the management of healthcare in aging societies. The worldwide increase in the number of elderly people is leading to increased demand for geriatric treatment as well as for support services for families in terms of care both in nursing homes and in the place of residence. The performance of ADLs stimulates self-esteem and helps individuals to maintain their status and roles in society, such as a parent, grandparent, employee, friend, or community member. Difficulties in carrying out ADLs are mainly caused by aging, injury, congenital disorders, stroke, surgery, or chronic disease.

The concept of ADLs was developed in the 1950s but was first mentioned by Marjorie Sheldon $(1935,30)$, who terms these actions "everyday activities which are necessary for ordinary living." The term "activities of daily living" was first used in 1949, by Edith Buchwald, as a part of an assessment checklist. In the 1950s, routine clinical assessments were broadened to include the evaluation of which activities a patient was able to perform. Measurement of what were termed "basic activities of daily living" (BADLs) was developed mainly to assess fitness for military duty in World War II and to determine levels of care for institutionalized elderly. In 1963 Sidney Katz and colleagues published an index with topics that represent primary biological functions. In 1969 Mortimer P. Lawton and Elaine M. Brody introduced the term "instrumental activities of daily living" (IADLs) as a result of increased interest in caring for older and disabled individuals in the community. Such IADLs are areas where dysfunctions due 
A. Klimczuk, Activities of Daily Living, [in:] C. Shehan (ed.), The Wiley-Blackwell Encyclopedia of Family Studies, Wiley-Blackwell, Hoboken, New Jersey 2016, pp. 22-25.

http://doi.org/10.1002/9781119085621.wbefs 143

to aging or illness first begin to cause problems with independence, but where these problems can be solved with the help of others. In the twenty-first century, a variety of ADL scoring systems are used in geriatrics, psychiatry, and rehabilitation programs for functional assessment in-home, long-term, or nursing home care, in occupational therapy, and in hospitalization.

\section{CATEGORIES OF ACTIVITIES OF DAILY LIVING}

Activities are usually subdivided into personal ADLs or BADLs and more complex domestic activities - IADLs. More recent techniques include a third group called advanced ADLs or expanded ADLs (EADLs), which are activities related to occupation, recreation, and community interactions. While the ability to perform ADLs and IADLs is self-reported, EADLs are assessed on a case-by-case basis in clinical settings. Differentiation between BADLs, IADLs, and EADLs is difficult due to differences in gender, age, and sociocultural perceptions of the variables included in the scales. There are also aids for ADLs - products, devices, and equipment springing from assistive technology or gerontechnology that are used to increase functional activities. Examples include self-care and rehabilitation equipment, and products that assist with vision, hearing, sensory, communication, safety, and learning needs.

The key activities included in BADLs are personal grooming (e.g., washing face, brushing teeth, cutting toenails, brushing hair, shaving, and bathing or showering); dressing and undressing; eating (feeding oneself; e.g., using eating utensils, drinking); transferring oneself from a bed to a chair and back; transferring oneself from a chair to a toilet; rising from a chair; getting in and out of bed; walking around one's residence; climbing stairs; being able to lift around five kilograms; maintaining bowel and bladder continence; and using the toilet. The level of ADL performance is used to predict survival and death, length of hospital stay, and type of hospital discharge in acute medical care. Examples of scales that measure BADLs are the Barthel Index, the Katz Index of ADL, the Kenny Self-Care Evaluation, and the PULSES profile.

Included in IADLs are more complex activities that require more concentration, skill, and coordination. They usually include the ability to use the telephone; shopping (for groceries and other items); food preparation; doing light housework (e.g., light cleaning, making beds, washing dishes); doing heavy housework (e.g., scrubbing floors, washing windows); doing laundry; using transportation (driving one's own car or using public transportation); proper use of medications; and money management. The most important scale is the Lawton-Brody IADL Scale. 
A. Klimczuk, Activities of Daily Living, [in:] C. Shehan (ed.), The Wiley-Blackwell Encyclopedia of Family Studies, Wiley-Blackwell, Hoboken, New Jersey 2016, pp. 22-25.

http://doi.org/10.1002/9781119085621.wbefs 143

Finally, EADLs were developed to go beyond the limitations of the ADL scales. The ADL scales contain a restricted range of items, whereas EADL scales are intended to represent the more extensive repertoire of skills required for living independently at home. While, in theory, understanding of the differentiation between ADLs and IADLs is clear, in practice, there is no agreement on the exact activities that should be included in such measures. Examples of EADL measures include the Frenchay Activities Index and the Nottingham Extended Activities of Daily Living Scale. These scales are criticized as being less reliable than others in terms of both total scores and individual items because they are based on the recall of activities undertaken during the preceding weeks. More recent tools include the Assessment of Living Skills and Resources, the Assessment of Motor and Process Skills, the Australian Therapy Outcome Measures, the Canadian Occupational Performance Measure, the Functional Independence Measure, and the Personal Care Participation and Resource Tool.

\section{EVALUATING ACTIVITIES OF DAILY LIVING}

Evaluations of ADLs are used for many reasons. Measures of ADL can provide an overview of the functional status of the patient, determine activity limitations, establish a baseline for treatment, be used as a guide for intervention planning, and be used as a guide for reporting and data management. Moreover, ADL scales can help with the evaluation of intervention programs, monitoring the progress of interventions, planning future treatment and discharge, measuring outcomes of rehabilitation, and providing data for evidence-based practice in medicine. An important challenge for practitioners is selecting the right tools for assessment. While some of the scales are standardized, some are more flexible checklists, so their outcomes can vary. Tools should be adjustable to aspects of interest and to particular groups; should possess validity, reliability, and sensitivity in measuring selected areas; should be simple to use; should generate clear operational definitions; and should allow communication of results with others.

Selection of a tool with which to measure ADLs should also consider the role of the family of the disabled or older person. For example, persons with dementia are often socially isolated. When dementia progresses, it becomes increasingly difficult to understand what the person is trying to communicate. The assessment process should identify the primary caregivers. Usually, these are members of the close family, who may feel frustrated and burdened. Evaluation of ADLs should help to define their role and the nature of the support they provide, taking information from social workers, nurses, or other experts. Measures of ADL can be also 
A. Klimczuk, Activities of Daily Living, [in:] C. Shehan (ed.), The Wiley-Blackwell Encyclopedia of Family Studies, Wiley-Blackwell, Hoboken, New Jersey 2016, pp. 22-25.

http://doi.org/10.1002/9781119085621.wbefs 143

influenced by obtaining reports from family members, though relatives sometimes do not know how individuals are functioning. Reported impairment may reflect the amount of stress the caregiver is experiencing rather than the actual status of the relative. Responses can be also influenced by a desire to protect the older person or a desire to obtain more assistance. In addition, elderly persons may want to present a favorable impression to the interviewer and may overreport family assistance and care.

SEE ALSO: Africa, Aging and Families in; Caregiving Experience; Disabilities and Families; Elder Care in the United States; Health and Families; Instrumental Activities of Daily Living; Theories of Aging

\section{REFERENCES}

Katz, Sidney, Amasa B. Ford, Roland W. Moskowitz, Beverly A. Jackson, and Marjorie W. Jaffe. 1963. "Studies of Illness in the Aged: The Index of ADL: A Standardized Measure of Biological and Psychosocial Function.” JAMA, 185(12): 914-19. DOI:10.1001/jama.1963.03060120024016.

Lawton, Mortimer P., and Elaine M. Brody. 1969. “Assessment of Older People: SelfMaintaining and Instrumental Activities of Daily Living.” The Gerontologist, 9(3): 17986. DOI:10.1093/geront/9.3_part_1.179.

Sheldon, Marjorie P. 1935. "A Physical Achievement Record for Use with Crippled Children." Journal of Health and Physical Education, 6(5): 30-60.

DOI:10.1080/23267240.1935.10620908.

\section{FURTHER READING}

Cress, Cathy J., ed. 2012. Handbook of Geriatric Care Management. Sudbury, MA: Jones \& Bartlett.

Feinstein, Alvan R., Bruce R. Josephy, and Carolyn K. Wells. 1986. "Scientific and Clinical Problems in Indexes of Functional Disability." Annals of Internal Medicine, 105(3): 413. DOI:10.7326/0003-4819-105-3-413.

Gallo, Joseph J., ed. 2006. Handbook of Geriatric Assessment. Sudbury, MA: Jones \& Bartlett.

Levine, Carol, ed. 2004. Family Caregivers on the Job: Moving beyond ADLs and IADLs. New York: United Hospital Fund of New York. 
A. Klimczuk, Activities of Daily Living, [in:] C. Shehan (ed.), The Wiley-Blackwell Encyclopedia of Family Studies, Wiley-Blackwell, Hoboken, New Jersey 2016, pp. 22-25.

http://doi.org/10.1002/9781119085621.wbefs 143

Mahoney, Florence I., and Dorothea W. Barthel. 1965. "Functional Evaluation: The Barthel Index." Maryland State Medical Journal, 14: 56-61.

McDowell, Ian. 2009. Measuring Health: A Guide to Rating Scales and Questionnaires. New York: Oxford University Press.

Moskowitz, Eugene, Mount Vernon, and Cairbre B. McCann. 1957. "Classification of disability in the chronically ill and aging." Journal of Chronic Disease, 5: 342-46. DOI:10.1016/0O21- 9681(57)90092-9.

Schoening, H., L. Anderegg, D. Bergstrom, M. Fonda, N. Steinke, and P. Ulrich. 1965. "Numerical Scoring of Self-Care Status of Patients." Archives of Physical Medicine and Rehabilitation, 46(10): 689-97. DOI:10.1097/00006199- 196811000-00117.

Wade, Derick T. 1992. Measurement in Neurological Rehabilitation. New York: Oxford University Press. 